\section{Case Reports in Ophthalmology}

Case Rep Ophthalmol 2020;11:229-233

DOI: $10.1159 / 000508236$

Published online: June 25, 2020

(C) 2020 The Author(s)

Published by S. Karger AG, Basel

www.karger.com/cop

This article is licensed under the Creative Commons Attribution-NonCommercial 4.0 International License (CC BY-NC) (http://www.karger.com/Services/OpenAccessLicense). Usage and distribution for commercial purposes requires written permission.

\title{
Combined Interventions for Nonorganic Visual Loss in a Case with Pseudo-Myopia: A Perspective from Vietnam
}

\author{
Hien Thu Thi Nguyen ${ }^{a}$ Tung Thanh Hoang ${ }^{b, c}$ Anh Phuong Tran ${ }^{a}$ \\ Huy Dinh Minh Tran ${ }^{\text {d, e }}$ \\ aVietnam National Institute of Ophthalmology, Hanoi, Vietnam; ${ }^{b}$ Hanoi Medical University, \\ Hanoi, Vietnam; 'The University of Sydney School of Medicine, Sydney, NSW, Australia; \\ dUniversity of Medicine and Pharmacy at Ho Chi Minh City, Ho Chi Minh City, Vietnam; \\ eHai Yen Vision Institute, Ho Chi Minh City, Vietnam
}

\section{Keywords}

Spasm of accommodation · Nonorganic visual loss · Atropine

\begin{abstract}
A previously healthy 10-year-old girl developed painless visual loss. She was diagnosed with a spasm of accommodation confirmed by cycloplegic refraction. She was prescribed low-dose atropine and again reported acute visual loss that was inconsistent with the level of daily function. She was referred to a pediatric psychiatrist with suspicion for a nonorganic visual disorder and was diagnosed with conversion disorder. She received psychotherapy and continued the treatment with low-dose atropine. Her visual acuity at distance returned to normal. Psychogenic visual loss can mimic organic disorders; hence, ophthalmologists should be aware of cases without the agreement between visual signs and daily manifestation.
\end{abstract}

(C) 2020 The Author(s)

Published by S. Karger AG, Basel 


\section{Case Reports in Ophthalmology}

\section{Introduction}

Spasm of accommodation causes pseudo-myopia without any accommodative effort, which was first described by von Graefe in 1856 [1]. This condition is a clinical diagnosis characterized by fluctuating refraction status and may be a presentation of a nonorganic visual disorder $[1,2]$. There are reports of neurological lesions causing accommodative spasm $[3,4]$.

In this report, we describe a patient who presented with excessive accommodation and subsequent sudden loss of vision without any organic deficit. She recovered after both psychotherapy and a course of atropine eye drops.

\section{Case Report}

A 10-year-old girl was admitted to the hospital due to painless vision loss in both eyes without a history of ocular or systemic diseases. Five months prior to presentation, she had been diagnosed with myopia and was prescribed spectacles based on manifest but not cycloplegic refraction (right eye: $-6.50 \mathrm{D}$; left eye $-6.25 \mathrm{D}$ ) (Fig. 1).

At the first visit, her best-corrected visual acuity (BCVA) with her current glasses was $20 / 100$ in the right eye and 20/80 in the left. Noncycloplegic auto-refraction measurements were $-8.50 /-0.50 \times 057 \mathrm{D}$ in the right eye and $-9.25 /-0.50 \times 153 \mathrm{D}$ in the left. She presented with full-eye movement, normal pupils with no APD, and normal anterior and posterior segment exams. She was prescribed $0.5 \%$ atropine in both eyes once daily; 5 days later, cycloplegic retinoscopy and auto-refraction findings were $+0.75 /-0.50 \times 007 \mathrm{D}$ in the right eye and $+0.75 /-0.50 \times 047 \mathrm{D}$ in the left. She reverted to an apparent myopic refraction with poor distance visual acuity when atropine was withdrawn over the next 3 weeks. She was diagnosed with bilateral accommodative spasm and again prescribed $0.5 \%$ atropine once daily with $+3.00 \mathrm{D}$ spectacles for near work. Over the next 2 weeks, her vision did not improve, but her cycloplegic refraction stabilized. Atropine dosage was lowered to $0.1 \%$ atropine once daily to minimize side effects. The patient then reported new visual loss 2 days after starting $0.1 \%$ atropine with BCVA of light perception in the right eye and hand motion at $0.2 \mathrm{~m}$ in the left.

On examination, no new abnormalities were found. MRIs of the brain and orbits with and without contrast were also unremarkable. She continued to conduct her daily activities, including schoolwork, without difficulty; at school, she was noticed to easily lose her temper and was prone to be talkative with attention-seeking behaviors. At our clinic, her visual response to surrounding stimuli was normal. Hence, we referred her to a pediatric psychiatrist with a clinical suspicion of functional visual loss. She was diagnosed with conversion disorder and underwent psychological therapy. Our final diagnosis was functional visual loss associated with spasm of accommodation.

Four weeks later ( 10 weeks after presentation to ophthalmology), her manifest refraction regressed to high myopia with low visual acuity; thus, she was restarted on atropine in conjunction with her psychotherapy. We tried different concentrations including $0.5 \%$ once daily ( 8 weeks) in addition to reading glasses, then $0.1 \%$ once daily ( 4 weeks) with the aim of reducing the side effects of topical atropine. During this course, the refraction gradually stabilized although reported acuity remained poor. Surprisingly, 6 months after presentation, her BCVA improved to $20 / 20$ in both eyes. We continued treatment with $0.01 \%$ atropine eye drops once daily, and no fluctuation of the refraction or BCVA were noted. On follow-up, her atropine drops were discontinued and visual acuity remained normal. 


\section{Case Reports in Ophthalmology}

\section{Discussion}

Spasm of accommodation has been described as a presentation of functional vision loss in children with mental illness [1]. Studies have reported that the prevalence of nonorganic visual loss in children was approximately $50 \%$ at a routine ophthalmological examination [5] and its annual incidence was roughly 3.5\% [6]. Even though the visual disorder of this patient was significant, we thought more about a psychogenic component since our clinical examination and imaging studies did not reveal any ophthalmic cause for her problem. Ophthalmologists should always remain suspicious of nonorganic visual loss in cases where there is an inconsistency between symptoms and findings.

In this case, psychotherapy alone was not enough to control pseudo-myopia and restore normal visual function, so we titrated different concentrations of atropine in combination. A recent study has revealed that $0.05,0.025$, and $0.01 \%$ atropine could prevent the progression of myopia [7]; nevertheless, there has not been any guideline for atropine concentration for accommodative spasm. Laria et al. [8] prescribed 1\% atropine once a day and spectacle of +1.0 in both eyes to control the accommodation of their patient with near reflex spasm. Shanker and Nigam [9] administered 1\% atropine twice a day for 1 week with punctual occlusion to relax the accommodation of a patient with the spasm of near reflex. However, Wakayama et al. [10] reported a higher incidence of adverse effect with $1 \%$ atropine compared to 0.5 and $0.25 \%$. Hence, we decreased the concentration due to the prolonged use of atropine in our patient. Fortunately, she recovered with combined pharmacologic and psychologic treatment.

This case represents the first report of the management of functional visual loss in a patient with accommodative spasm in Vietnam. The sequence of findings and interventions may help other physicians to manage such patients and provide a practical lesson for clinicians, especially those from developing settings. Our strengths were the close monitoring of the patient and the use of a variety of atropine concentrations. Ideally, consultation with a psychiatrist should have occurred earlier; nonetheless, we do not work in a general hospital, so it took 4 weeks for the consultation to the pediatric hospital. Another option, not available to us, would be to perform a visual evoked potential (VEP) as an objective assessment, as VEP has shown to be useful in differentiating functional from organic visual loss [5].

\section{Conclusion}

Ophthalmologists should be aware of underlying psychological and psychiatric issues in order to refer the patient properly and to optimize care.

\section{Acknowledgments}

The authors express the deepest gratitude to Prof. Prem Subramanian, Department of Ophthalmology, University of Colorado School of Medicine, Aurora, CO, USA, for having edited the scientific language of this paper. 


\section{Case Reports in Ophthalmology}

\begin{tabular}{l|l}
\hline DOI: $10.1159 / 000508236$ & (c) 2020 The Author(s). Published by S. Karger AG, Basel \\
www.cop
\end{tabular}
www.karger.com/cop

Nguyen et al.: Interventions for Nonorganic Visual Loss with Pseudo-Myopia

\section{Statement of Ethics}

The report strictly follows the tenets of the World Medical Association Declaration of Helsinki. The consent form has been provided and signed by the parents of the patient.

\section{Disclosure Statement}

The authors have no conflicts of interest to declare.

\section{Funding Sources}

The authors certify that they have no affiliations with, or involvement in, any organization or entity with any financial or non-financial interest in the subject matter discussed.

\section{Author Contributions}

Hien Thu Thi Nguyen and Anh Phuong Tran reviewed the patient data at each appointment and provided the raw data. Tung Thanh Hoang and Huy Minh Dinh Tran were in charge of analyzing the data, reviewing the medical literature, writing,, and editing the manuscript. All authors approved the final version of the manuscript for publication.

\section{References}

1 Savin LH. Functional spasm of accommodation. Br J Ophthalmol. 1959 Jan;43(1):3-8.

2 Goldstein JH, Schneekloth BB. Spasm of the near reflex: a spectrum of anomalies. Surv Ophthalmol. 1996 JanFeb;40(4):269-78.

3 Monteiro ML, Curi AL, Pereira A, Chamon W, Leite CC. Persistent accommodative spasm after severe head trauma. Br J Ophthalmol. 2003 Feb;87(2):243-4.

4 Gedar Totuk OM, Aykan U. A new treatment option for the resistant spasm of accommodation: clear lens extraction and multifocal intraocular lens implantation. Int J Ophthalmol. 2018 Jan;11(1):172-4.

5 Somers A, Casteels K, Van Roie E, Spileers W, Casteels I. Non-organic visual loss in children: prospective and retrospective analysis of associated psychosocial problems and stress factors. Acta Ophthalmol. 2016 Aug;94(5):e312-6.

6 Daniel MC, Coughtrey A, Heyman I, Dahlmann-Noor AH. Medically unexplained visual loss in children and young people: an observational single site study of incidence and outcomes. Eye (Lond). 2017 Jul;31(7):1068-73.

7 Yam JC, Jiang Y, Tang SM, Law AK, Chan JJ, Wong E, et al. Low-Concentration Atropine for Myopia Progression (LAMP) Study: A Randomized, Double-Blinded, Placebo-Controlled Trial of $0.05 \%, 0.025 \%$, and 0.01\% Atropine Eye Drops in Myopia Control. Ophthalmology. 2019 Jan;126(1):113-24.

8 Laria C, Merino-Suárez ML, Piñero DP, Gómez-Hurtado A, Pérez-Cambrodí RJ. Botulinum Toxin as an Alternative to Treat the Spasm of the Near Reflex. Semin Ophthalmol. 2015;30(5-6):393-6.

9 Shanker V, Nigam V. Unusual Presentation of Spasm of Near Reflex Mimicking Large-Angle Acute Acquired Comitant Esotropia. Neuroophthalmology. 2015 Jul;39(4):187-90.

10 Wakayama A, Nishina S, Miki A, Utsumi T, Sugasawa J, Hayashi T, et al. Incidence of side effects of topical atropine sulfate and cyclopentolate hydrochloride for cycloplegia in Japanese children: a multicenter study. Jpn J Ophthalmol. 2018 Sep;62(5):531-6. 
Case Reports in Ophthalmology
Case Rep Ophthalmol 2020;11:229-233

(c) 2020 The Author(s). Published by S. Karger AG, Basel www.karger.com/cop

Nguyen et al.: Interventions for Nonorganic Visual Loss with Pseudo-Myopia

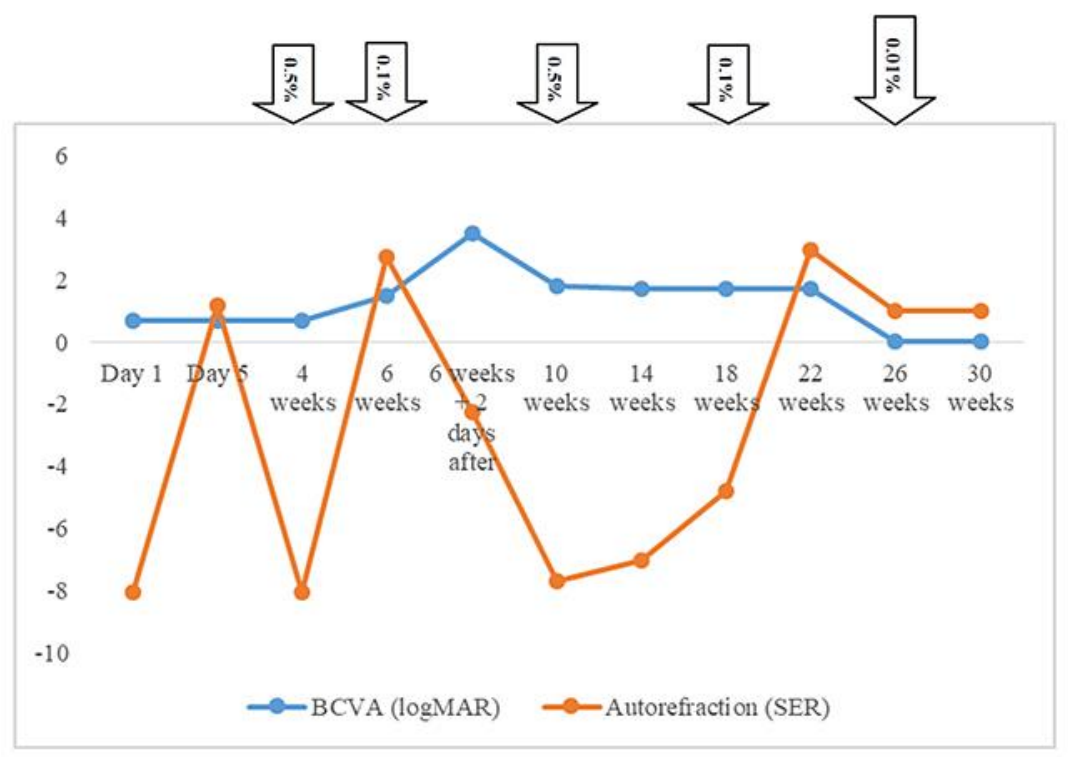

a
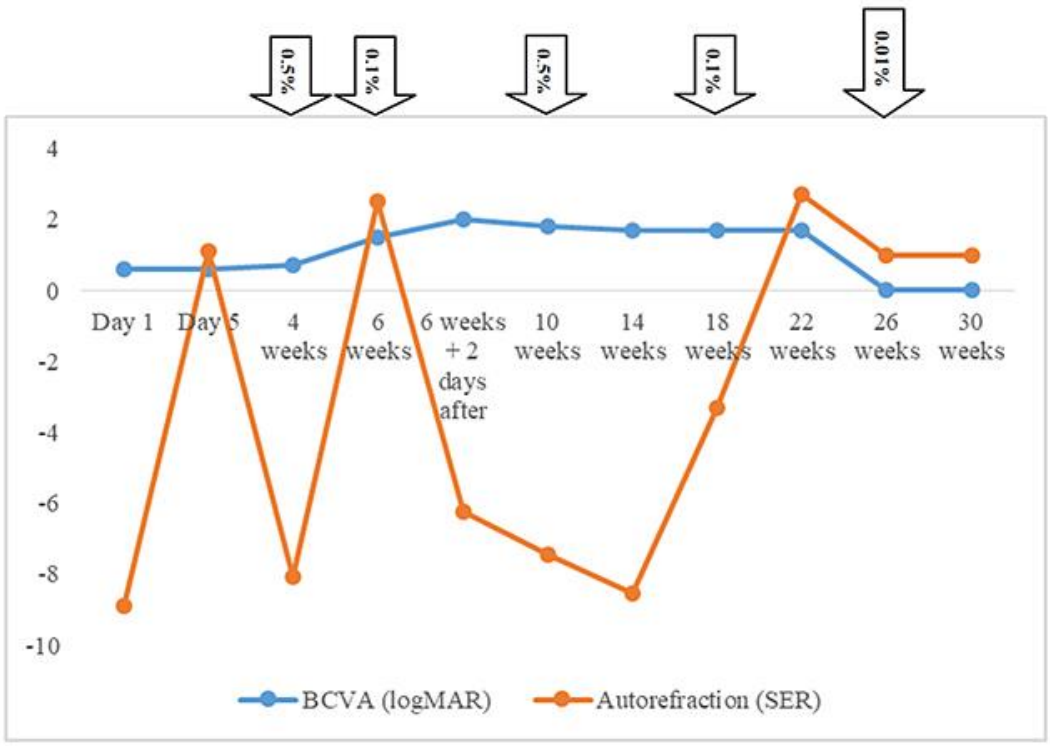

b

Fig. 1. The fluctuation of visual acuity and auto-refraction parameters in the right (a) and left (b) eye with various concentrations of atropine. 